\title{
Wetter then drier in some tropical areas
}

\author{
Article
}

Accepted Version

Hawkins, E., Joshi, M. and Frame, D. (2014) Wetter then drier in some tropical areas. Nature Climate Change, 4 (8). pp. 646647. ISSN 1758-678X doi:

https://doi.org/10.1038/nclimate2299 Available at https://centaur.reading.ac.uk/38256/

It is advisable to refer to the publisher's version if you intend to cite from the work. See Guidance on citing.

To link to this article DOI: http://dx.doi.org/10.1038/nclimate2299

Publisher: Nature Publishing Group

All outputs in CentAUR are protected by Intellectual Property Rights law, including copyright law. Copyright and IPR is retained by the creators or other copyright holders. Terms and conditions for use of this material are defined in the End User Agreement.

\section{www.reading.ac.uk/centaur}

\section{CentAUR}

Central Archive at the University of Reading

Reading's research outputs online 


\section{Non-monotonic precipitation projections in the ITCZ region}

Ed Hawkins ${ }^{1}$, Manoj Joshi ${ }^{2}$, Dave Frame ${ }^{3}$

Correspondence to Nature Climate Change, revised

1. National Centre for Atmospheric Science, Department of Meteorology, University of Reading, UK

2. Centre for Ocean and Atmospheric Sciences, School of Environmental Sciences, University of East Anglia, UK

3. New Zealand Climate Change Research Institute, School of Geography, Environment and Earth Sciences, University of Wellington, New Zealand

\section{To the Editor -}

As the climate warms, projected changes in precipitation are generally assumed to be monotonic with respect to global temperature changes. However, using an example in South America, we demonstrate that, under a high emissions scenario, rainfall changes in some regions can actually be non-monotonic, which has important implications for biodiversity, the carbon cycle and longterm climate policy.

The latitudinal position of the Inter-Tropical Convergence Zone (ITCZ) is projected to move equatorwards in response to a warming climate ${ }^{1,2,3}$, although there is uncertainty as to how far and how fast. As it does so, some low-latitude regions may find that the rainfall that they receive first increases in accordance with the 'wet get wetter' paradigm, but then decreases as the ITCZ moves over and past them; such regions will experience non-monotonic changes in precipitation with time. We examine this phenomenon using multi-centennial projections of precipitation from different global climate models (GCMs) (see Supplementary Information).

Non-monotonic changes in precipitation are pronounced over the oceans after the year 2100 especially in the tropical Atlantic (Fig. S1) and Pacific - but they also occur over land regions where impacts on infrastructure and ecosystems will be far more significant. As an example, several GCMs display evidence of non-monotonic changes for tropical South America (Fig. 1). Specifically, several simulations suggest an increase in precipitation near $5^{\circ} \mathrm{N}$ until the year 2100 , followed by a decrease, but temperatures exhibit a monotonic increase in this region (Fig. S2).

Interestingly, the two finest resolution models available (HadGEM2-ES and CCSM4) show clear nonmonotonic precipitation signals, suggesting that the effect may be somewhat dependent on model resolution. However, IPSL-CM5A-LR also shows a similarly clear signal. In any case, this effect would be overlooked by simply averaging a multi-model ensemble. Uncertainties in precipitation projections for the next century on regional spatial scales are dominated by model response uncertainty and internal climate variability, rather than emission scenario uncertainty ${ }^{4}$.

The region identified in Fig. 1 is a biodiversity hotspot with several 'irreplaceable protected areas', and is home to many threatened species (including terrestrial mammals, amphibians, birds, and plants $^{6}$ ), all of which may be directly or indirectly sensitive to changes in precipitation ${ }^{7,8}$. For instance, an eventual reduction in precipitation could result in accelerated decreases in net primary productivity (NPP) and vegetation cover in regions where NPP already decreases during the $21^{\text {st }}$ century ${ }^{9}$, while causing non-monotonic changes in NPP elsewhere. Profound and surprising changes 
in local habitats, as well as changes in both the local and global carbon budgets during the $21^{\text {st }}$ century ${ }^{10}$ could therefore be driven by non-monotonicity in precipitation change.

Evidence for non-monotonically changing climate variables exists in climate model projections of tropical South America. Many projections of impacts and vulnerabilities resulting from climate change, such as those produced by integrated assessment models ${ }^{11}$, can be expected to fail to capture such dynamic effects described, especially if they are based on linear regressions, pattern scaling or snapshots of future patterns of change at a specific point in the future (such as 2100). Decision makers should be aware that long-term changes may oppose or even reverse near-term changes, driving potentially unexpected impacts in some of the most unique and irreplaceable habitats in the world.

\section{Acknowledgements}

EH is supported by a NERC Advanced Research Fellowship and MMJ acknowledges support from University of Wellington. We acknowledge the World Climate Research Programme's Working Group on Coupled Modelling, which is responsible for CMIP, and we thank the climate modelling groups for producing and making available their model output. For CMIP the U.S. Department of Energy's Program for Climate Model Diagnosis and Intercomparison provides coordinating support and led development of software infrastructure in partnership with the Global Organization for Earth System Science Portals.

WEST AMAZONIA PRECIPITATION | JJA | 80W to 65W | RCP8.5
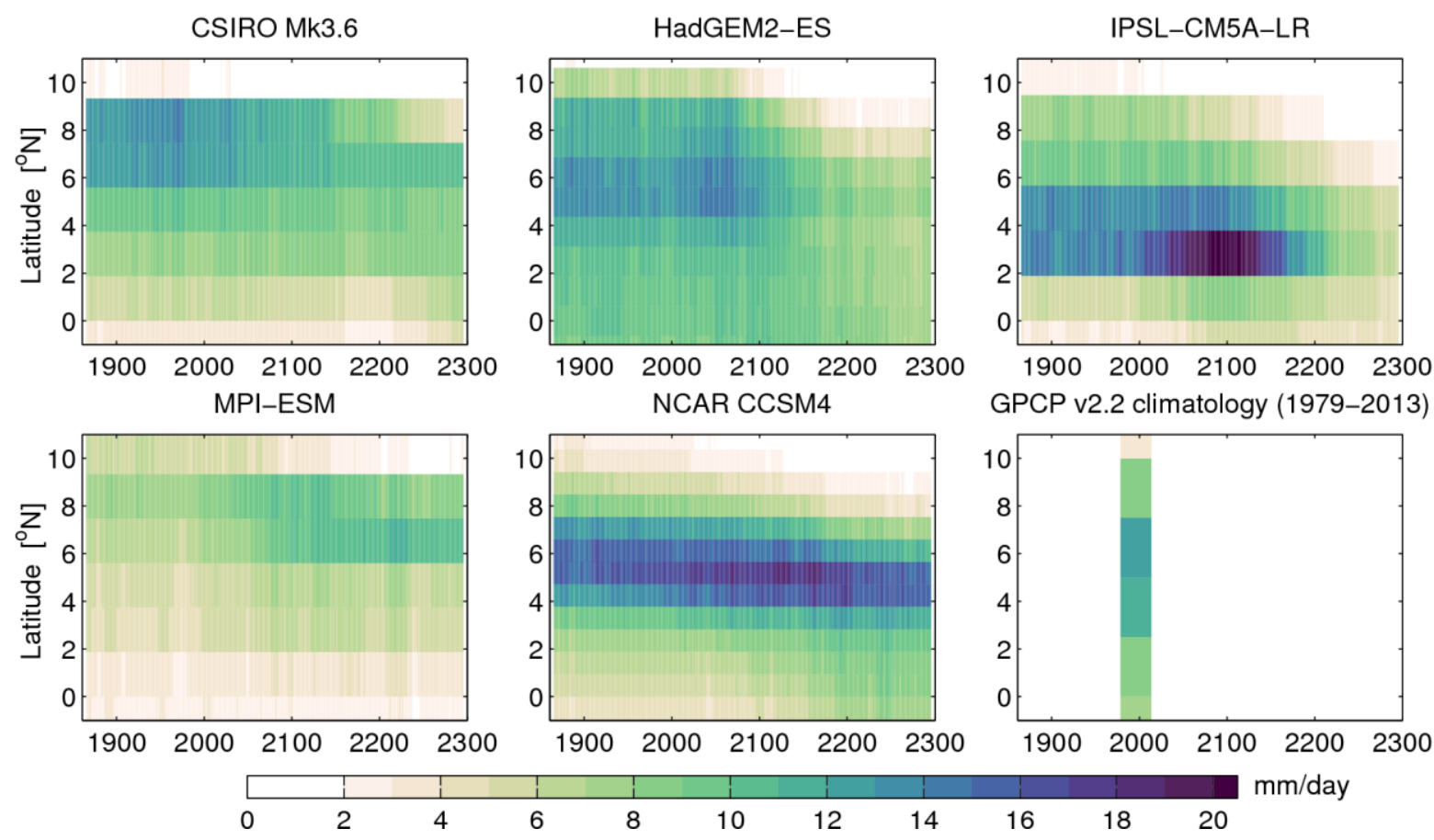

Figure 1: Non-monotonic precipitation projections. Simulated precipitation for boreal summer ( $\mathrm{mm} /$ day, running decadal means for JJA) averaged over land regions in northern South America (80W to 65W) in five GCMs using the historical (1860-2005) and RCP8.5 (2006-2300) forcing pathways. A climatological estimate from the GPCP v2.2 observations ${ }^{12}$ for $1979-2013$ is shown for the same region (bottom right). 


\section{REFERENCES}

${ }^{1}$ Chou, C, Neelin, JD, Chen, C \& Tu, J, J. Climate, 22, 1982 (2009)

${ }^{2}$ Frierson, DMW \& Hwang, Y-T, J. Climate, 25, 720 (2012)

${ }^{3}$ Knutti, R, et al., Chapter 12 in Climate Change 2013: The Physical Science Basis, The IPCC $5^{\text {th }}$ Assessment Report, Cambridge University Press (2013)

${ }^{4}$ Hawkins, E \& Sutton, R, Climate Dynamics, 37, 407 (2011)

${ }^{5}$ Le Saout, S, et al., Science, 342, 803 (2013)

${ }^{6}$ Ricketts, T, et al., PNAS, 102, 18497 (2005)

${ }^{7}$ Higgins, PAT, Global Ecology and Biogeography, 16, 197 (2007)

${ }^{8}$ Mantyka-pringle, CS, Martin, TG \& Rhodes, JR, Glob. Change. Biology, 18, 1239 (2012)

${ }^{9}$ Mahli, Y, et al., Proc. Nat. Acad. Sci. 106, 20610 (2009)

${ }^{10}$ Cox, PM, Betts, RA, Jones, CD, Spall, SA \& Totterdell, IJ, Nature, 408, 184 (2000)

${ }^{11}$ Tol, RSJ, Environmental and Resource Economics 21, 25 (2002)

${ }^{12}$ Adler, RF, et al., J. Hydrometeor., 4, 1147 (2003) 